\title{
The hip trial: psychosocial consequences for mothers of using ultrasound to manage infants with developmental hip dysplasia
}

\author{
F Gardner, C Dezateux, D Elbourne, A Gray, A King, A Quinn, on behalf of the Collaborative Hip \\ Trial Group
}

Arch Dis Child Fetal Neonatal Ed 2005;90:F17-F24. doi: 10.1136/adc.2002.025684

See end of article for authors' affiliations

.....................

Correspondence to: Dr Gardner, Department of Social Policy and Social Work University of Oxford,, Barnett House, Wellington Square, Oxford OXI 2ER, UK; frances.gardner@socres. ox.ac.uk

Accepted 30 May 2004
Background: The hip trial aimed to assess clinical effectiveness, economic and psychosocial costs, and benefits of ultrasound imaging (US) compared with conventional clinical assessment alone to guide the management of infants with neonatal hip instability.

Objective: To report on psychosocial consequences for mothers and the developing mother-child relationship of US, and associations between abduction splinting and maternal psychosocial distress.

Design: Multicentre randomised controlled trial.

Setting: Thirty three hospitals in the United Kingdom and Ireland.

Participants, interventions: A total of 629 infants with neonatal hip instability randomised to US examination or clinical assessment alone before treatment decision. Questionnaires were completed by $561(89 \%)$ mothers at 8 weeks and $494(79 \%)$ at 1 year.

Main outcome measures: Anxiety, postnatal depression, parenting stress assessed by standardised questionnaires. Maternal concerns about hip problems were assessed using the Infant hip worries inventory.

Results: At 8 weeks, there were no differences between US and non-US groups of the trial in maternal anxiety (mean difference (MD) - 1.2,95\% confidence interval (Cl) - 3.2 to 0.8), depression (MD 0.0,95\% $\mathrm{Cl}-0.7$ to 0.8 ), parenting stress (MD $-1.2,95 \% \mathrm{Cl}-2.8$ to 0.4 ), or other measures. The same pattern was evident at 1 year. In an explanatory analysis, early splinting was associated with increased anxiety at 8 weeks (MD 3.8, 95\% Cl 1.7 to 5.9) and increased level of hip worries at 8 weeks (MD 6.8, 95\% Cl 5.6 to 7.9 ) and 1 year (MD 1.3, 95\% $\mathrm{Cl} 0.3$ to 2.4$)$.

Conclusions: Although early splinting is associated with maternal anxieties, US is not associated with any increase or reduction in psychosocial effects on mothers. Together with the clinical findings, this suggests that the use of US allows reduction in splinting rates without increased risk of adverse clinical or psychosocial outcomes.
$\mathrm{D}$ ecisions about the implementation of health care policies for children should be informed by good evidence about their effects. Such effects may include clinical outcomes for the children, economic implications for the health services, and consequences for the principal caregivers in terms of costs to the families and psychosocial effects on the mothers. If the clinical effects are positive but the magnitude of the benefit is moderate or small, the nonclinical effects may be of greater potential importance to policy making and implementation. We compare the psychosocial consequences for mothers of different policies for the management of hip instability in infants who participated in a randomised controlled trial of ultrasound imaging- the hip trial.

In the United Kingdom, it is recommended that all newborn infants receive a clinical screening examination of their hips shortly after birth and at 6-8 weeks of age. This examination is to identify infants with neonatal hip instability (NHI) who are considered to be at increased risk of subsequent hip displacement and developmental dysplasia of the hip (DDH). ${ }^{12} \mathrm{NHI}$ is one of the most commonly diagnosed conditions that parents of a newborn baby may face. ${ }^{34}$ It usually resolves without treatment during the first weeks of life. However, abnormalities may persist in some babies and, unless treated early with abduction splinting, may result in hip displacement in later childhood when surgical treatment is associated with a poorer outcome, especially if initiated after walking age. Although most children with NHI are not at increased risk of hip displacement, in practice it is difficult to identify those who are. Thus some receive unnecessary treatment with abduction splinting with the possibility of iatrogenic risks for the child and psychosocial consequences for the family. ${ }^{5}$ Given this uncertainty, ${ }^{6}$ there has been increasing use of ultrasound imaging to guide the management of babies who on clinical screening are judged to have NHI. ${ }^{7}$ However, until recently, evidence to support this policy was limited to one small single centre randomised clinical trial, ${ }^{8}$ which did not address outcomes relevant to psychosocial consequences for parents. The aim of the hip trial was to reliably assess the clinical, psychosocial, and cost effectiveness of ultrasound imaging in this context. The methods and results for the study of clinical effectiveness and hospital costs have been detailed elsewhere, and are therefore only summarised briefly in the summary box.

The psychosocial consequences for mothers of these policies are potentially important in the management of NHI. Firstly, this condition is usually identified during the

Abbreviations: DDH, developmental dysplasia of the hip; EPDS, Edinburgh postnatal depression scale; NHI, neonatal hip instability; PSI, parenting stress index; STAl, Spielberger state-trait anxiety inventory 
first few days of life, presenting mothers with additional stress at a time of a major life event. Secondly, although we could find no published studies reporting the psychosocial effects of NHI, some studies suggest that infant disorders may increase maternal anxiety, postnatal depression, and marital difficulties, ${ }^{10}{ }^{11}$ whereas other studies suggest that these reactions may be mediated by social factors rather than medical problems. ${ }^{12}{ }^{13}$ Where adverse maternal reactions occur, these may in turn have longer term effects on the emerging relationship between mother and child, for example by affecting the mother's enjoyment of the baby, and the eventual quality of attachment. ${ }^{14}$ Moreover, chronic physical conditions in childhood, ${ }^{15}{ }^{16}$ including surgically treated $\mathrm{DDH}_{1}{ }^{17}$ may increase the risk of childhood behavioural disorders, possibly through the mechanism of adversely influencing early mother-child interactions. Finally, parental experiences commonly reported to steps (a UK based charity offering support to parents of children with lower limb abnormalities, including NHI and $\mathrm{DDH}^{18}$ ) suggest that diagnosis and, particularly, treatment of NHI may place great stress on some mothers. Concerns include anxiety about the future and practical difficulties when managing a newborn baby in a splint appliance, which may cause the baby to be irritable and hard to feed, cuddle, bathe, and transport. Thus the splint treatment, as well as the condition itself, may have adverse effects on the mother-child relationship, but these have not been systematically investigated.

It was recognised at the outset of the hip trial that policies about ultrasound imaging in this context may lead to either beneficial or harmful psychosocial consequences for mothers, mediated in different ways. On the one hand, imaging may reduce maternal distress, because of the resulting reduction in splint treatment rates, or because ultrasound may reassure mothers that decisions about management of suspected

Table 1 Outcome measures and timing of administration of measures

\begin{tabular}{|c|c|c|}
\hline Scale (number of items) & 8 weeks & 1 year \\
\hline $\begin{array}{l}\text { EPDS (9) } \\
\text { PSI } \\
\text { PSI subscales } \\
\text { Child moody (5) } \\
\text { Mother sense of competence } \\
\text { (11) } \\
\text { Sense of attachment (5) } \\
\text { Spouse problems (6) } \\
\text { Child seen as rewarding (6) } \\
\text { Infant hip worries inventory (12) }\end{array}$ & $\begin{array}{l}\sqrt{ } \\
(\text { items } 1-11)^{*}\end{array}$ & $\begin{array}{l}\text { b } \\
\sqrt{ } \\
\sqrt{\text { (items } 1,2,8,9,} \\
10,12 \text { ) }\end{array}$ \\
\hline \multicolumn{3}{|c|}{$\begin{array}{l}\text { Items of the infant hip worries inventory: } \\
\text { 1. I feel upset when people ask me about my baby's hips } \\
\text { 2. I worry that I might do something to hurt my baby's hips } \\
\text { 3. I feel upset when I look at my baby } \\
\text { 4. I find it difficult to feed my baby } \\
\text { 5. I find it difficult to cuddle my baby } \\
\text { 6. I find it difficult to wash my baby } \\
\text { 7. I worry about whether my baby is comfortable } \\
\text { 8. I worry before each hospital visit related to my baby's hip } \\
\text { 9. I worry about the effect the hip instability might have on my baby in } \\
\text { 10. I was very upset when I was first told that my baby had an unstable } \\
\text { 11. In the last } 8 \text { weeks, I have had helpful people to turn to about my } \\
\text { 12. I worry about my child's walking. }\end{array}$} \\
\hline $\begin{array}{l}\text { Responses scored on five point scc } \\
\text { disagree). } \\
\text { *Item } 11 \text { reverse scored; omitted } f \\
\text { with other items. } \\
\text { EPDS, Edinburgh postnatal depre }\end{array}$ & 5 & $\begin{array}{l}\text { gly agree) to } 1 \text { (strongly } \\
\text { cause of low correlation } \\
\text { parenting stress index. }\end{array}$ \\
\hline
\end{tabular}

instability had been made using the "best" technology. This could be reassuring for mothers who were told the ultrasound was normal, as well as to those whose babies were treated. On the other hand, a potential delay in making a management decision while waiting for ultrasound imaging to be undertaken may lead to increased maternal anxiety. Finally, for other mothers, the decision to leave the child untreated-even if informed by ultrasound imagingmay increase maternal anxiety. Treatment with abduction splinting, although stressful, may nevertheless reassure mothers that everything possible is being done.

In the light of this complex set of possible effects, this paper addresses two main questions. Firstly, are there beneficial or harmful effects of a policy of ultrasound imaging on maternal distress and perceptions of difficulties in the mother-infant relationship? Secondly, what mechanisms may be associated with maternal distress in the context of the hip trial? Specifically we wished to explore whether early treatment with abduction splinting is associated with higher levels of maternal distress, and with difficulties in the mother-child relationship, both in the early weeks and by 1 year of age.

\section{METHODS}

Approval was obtained from local research ethics committees for all participating centres. We requested that all mothers who consented to participate in the trial be given a brief questionnaire by local clinicians at trial entry. In the course of the trial, it became clear that local clinicians were giving the first questionnaire to mothers to complete at various times before and after randomisation and treatment. Information from these questionnaires did not therefore provide information at baseline consistently, and is not presented.

A total of 629 babies with clinically detected NHI were randomised to a policy of ultrasound imaging versus conventional clinical assessment alone, which all babies received. Mothers were asked to complete postal questionnaires when their baby was aged 8 weeks and 1 year. Nonresponders were sent two further reminders, including one from steps.

\section{Development of outcome measures for the study}

Pilot interviews were carried out with parents whose infants were at various stages in the management of hip problems, with clinicians in a specialist outpatient clinic, and with steps to identify issues of most concern to parents of babies with NHI. Parental concerns included feeling shocked, sad, or anxious about the baby, and about possible surgical treatment or disability; feeling anxious before each hospital visit, or feeling that support or information had been inadequate. Mothers of babies treated with abduction splinting reported

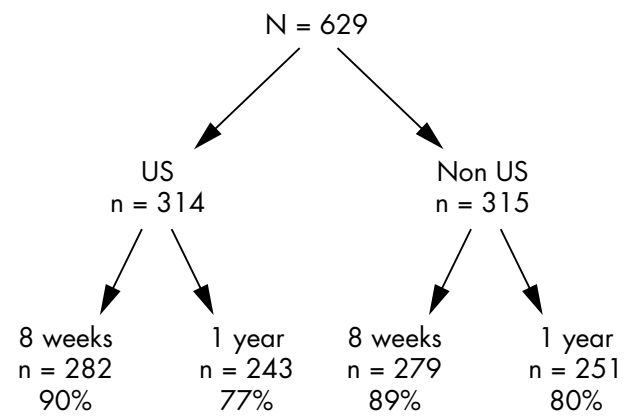

Figure 1 Response rates to psychosocial questionnaires by allocation at 8 weeks and 1 year. US, Infant randomised to ultrasound examination; non US, infant had clinical assessment only. 
Table 2 Characteristics of mothers and babies by random allocation

\begin{tabular}{|c|c|c|}
\hline & \multicolumn{2}{|c|}{ Random allocation } \\
\hline & $\begin{array}{l}\text { Ultrasound } \\
(n=282)\end{array}$ & $\begin{array}{l}\text { No ultrasound } \\
(n=279)\end{array}$ \\
\hline \multicolumn{3}{|l|}{ Marital status } \\
\hline Married/cohabiting & $219(77.7)$ & $223(79.9)$ \\
\hline Widowed/divorced/single & $25(8.9)$ & $24(8.6)$ \\
\hline Not known & $38(13.5)$ & $32(11.5)$ \\
\hline \multicolumn{3}{|l|}{ Profession of mother } \\
\hline Non-manual & $154(54.6)$ & $157(56.3)$ \\
\hline Manual & $34(12.1)$ & $38(13.6)$ \\
\hline Other & $53(18.8)$ & $48(17.2)$ \\
\hline Not known & $41(14.5)$ & $36(12.9)$ \\
\hline Maternal age (years) ${ }^{*} \ddagger$ & $29.6(5.6)$ & $29.0(5.6)$ \\
\hline Age of baby at trial entry (day) + - & $4.0(1.0-18.3)$ & $6.0(1.0-20.0)$ \\
\hline Sex of baby, female & $199(70.6)$ & $203(72.8)$ \\
\hline Birth weight $(\mathrm{g})^{\star} \S$ & $3419(495)$ & $3369(552)$ \\
\hline Gestational age at delivery (weeks)* & $39.6(1.5)$ & $39.5(1.6)$ \\
\hline Bilateral abnormality & $85(30.1)$ & $95(34.1)$ \\
\hline Clinical diagnosis at trial entry dislocatable or worse & $162(57.4)$ & $168(60.2)$ \\
\hline $\begin{array}{l}\text { Clinical suspicion at trial entry sufficient to warrant early } \\
\text { prophylactic splinting }\end{array}$ & $86(30.5)$ & $80(28.7)$ \\
\hline \multicolumn{3}{|l|}{$\begin{array}{l}\text { Values are number (\%) unless otherwise stated. } \\
{ }^{*} \text { Values are mean (SD). } \\
+ \text { Values are median (interquartile range). } \\
\mp n=271,266 ; \cdot \mathrm{I}=282,279 ; \xi n=282,278 .\end{array}$} \\
\hline
\end{tabular}

feelings of incompetence as a parent, as well as practical difficulties with feeding, bathing, and transportation. Some mothers worried that their baby was uncomfortable and fractious because of the splint. Many had concerns related to their relationship with the baby. For example, some found it very upsetting to see their baby in a splint, others were sad that the splint prevented them from easily cuddling, bathing, and enjoying the baby during the early months of life. This pilot work guided our outcome measures. Standardised instruments were used where available.

\section{Parenting stress}

To assess mothers' feelings of attachment to the baby, sense of competence as a parent, and perception of the baby as "moody", we used the relevant subscales of the parenting stress index $\left(\mathrm{PSI}^{19}\right)$ at 8 weeks and 1 year. This is widely used and has extensive data on reliability and validity. It was developed for assessing stress in the parent-child relationship in clinical settings, in the context of childhood illness and disability. ${ }^{20-22}$ The "total" score used here represents the sum of the subscales administered at each time point, which are detailed in table 1 . At 1 year we also assessed mothers' views of the marital relationship, and explored further aspects of the attachment relationship, by asking about how rewarding the mother found the child, using two further scales of the PSI. These two scales were introduced at 1 year for a number of reasons. Firstly, we did not want to overburden mothers at 8 weeks. Secondly, the questions in the "child rewarding" scale were not appropriate to a neonate. Thirdly, we felt that any long lasting effects of hip problems on the marital relationship would be more likely to be identified at 1 year, rather than 8 weeks.

\section{Maternal anxiety}

This was assessed at 8 weeks and 1 year of age using the six item short form of the "state" part of the Spielberger statetrait anxiety inventory (STAI). ${ }^{23}$ This instrument has been used widely in studies of health screening, is reliable and well validated, and correlates $(r=0.9)$ very highly with the full form of the STAI (score range 20-80, normative mean 35, clinical range $>42^{20}$ ).

\section{Maternal depression}

This was assessed at 8 weeks and 1 year using the Edinburgh postnatal depression scale (EPDS ${ }^{24}$ ), a widely used and wellvalidated 10-item questionnaire for detecting depression in the postnatal period. Although originally developed for face to face use, it has been validated for postal administration in large community studies ${ }^{25} 26$ and for use outside the postnatal period, with one year olds. ${ }^{27}$ The score range is $0-30$, and a range of cut offs have been used for different purposes, including $12 / 13$ to detect clinical depression in many large screening studies, as well as a lower cut off of $9 / 10$ in others. ${ }^{28}{ }^{29}$ We omitted one question about self harm that we felt was inappropriate for a postally administered questionnaire in this context. Other studies have found little effect on rates of depression with this item omitted. ${ }^{30}$ Moreover, given that the aim of the present study is to compare two randomised groups, rather than make comparisons with other samples, the omission of an item would not greatly affect interpretation of the results, and to aid interpretation, we analysed the EPDS by continuous scores, rather than cut offs.

\section{Hip worries}

These were assessed at 8 weeks and 1 year using a set of 12 hip specific questions (the infant hip worries inventory), which we devised to directly reflect maternal concerns reported in the pilot interviews. The inventory was refined after piloting with mothers of babies with NHI, and after consultation with steps. As item 11, which asks about social support at 8 weeks, performed poorly in reliability analyses, we report 8 week data for the hip worries inventory with item 11 omitted. This item was not administered at 1 year. At 1 year, we also omitted items on splinting, as few babies undergo treatment at this age, and added one question asking mothers if they worried about their baby's walking. There were 10 items at 8 weeks, and six at 1 year included in the analysis, as detailed in table 1. Each answer was scored from 1 (least upset or worried) to 5 (most upset or worried). The scale has high internal consistency $(\alpha=0.83$ at 8 weeks and 0.85 at 1 year $)$, and high stability over time $(r=0.58$, between 8 weeks and 1 year), and hence we summarised the item scores to give a total inventory score. In all questionnaires, higher scores represent more distress. 
Table 3 Psychosocial scores at 8 weeks by random allocation

\begin{tabular}{|c|c|c|c|c|c|c|c|c|c|}
\hline & \multicolumn{9}{|c|}{ Random allocation } \\
\hline & \multicolumn{3}{|c|}{ Ultrasound } & \multicolumn{3}{|c|}{ No ultrasound } & \multirow[b]{2}{*}{$p$ Value } & \multirow[b]{2}{*}{$\mathbf{R R}$} & \multirow[b]{2}{*}{$95 \% \mathrm{Cl}$} \\
\hline & $\mathrm{N}$ & $\%$ & & $\mathbf{N}$ & $\%$ & & & & \\
\hline \multirow[t]{2}{*}{ Anxiety in clinical range } & $72 / 281$ & 26 & & $78 / 274$ & 28 & & 0.45 & 0.90 & 0.68 to 1.18 \\
\hline & No & Mean & SD & No & Mean & SD & p Value & MD & $95 \% \mathrm{Cl}$ \\
\hline Anxiety scale (STAI) & 281 & 34.5 & 11.8 & 274 & 35.6 & 12.2 & 0.26 & -1.2 & -3.2 to 0.8 \\
\hline Depression (EPDS) & 279 & 7.5 & 4.4 & 277 & 7.4 & 4.7 & 0.95 & 0.0 & -0.7 to 0.8 \\
\hline Parenting stress total (PSI) & 272 & 41.4 & 8.8 & 266 & 42.6 & 10.3 & 0.15 & -1.2 & -2.8 to 0.4 \\
\hline PSI sense competence & 279 & 22.4 & 5.6 & 273 & 22.9 & 6.6 & 0.34 & -0.5 & -1.5 to 0.5 \\
\hline PSI attachment & 279 & 9.5 & 2.5 & 273 & 9.7 & 2.7 & 0.41 & -0.2 & -0.6 to 0.3 \\
\hline PSI child moody & 273 & 9.5 & 3.1 & 276 & 9.8 & 3.2 & 0.29 & -0.3 & -0.8 to 0.3 \\
\hline Hip worries inventory & 280 & 26.1 & 7.2 & 277 & 27.1 & 7.2 & 0.09 & -1.0 & -2.2 to 0.2 \\
\hline
\end{tabular}

MD, Mean difference; RR, relative rate; Cl, confidence interval; EPDS, Edinburgh postnatal depression scale; PSI, parenting stress index; STAI, Spielberger statetrait anxiety inventory.

\section{Statistical methods}

The sample size for the psychosocial outcomes was based on the power calculations for the clinical outcomes. ${ }^{9}$ In the first set of analyses presented in this paper, we compared psychosocial outcomes in the ultrasound and non-ultrasound arms of the trial on an "intention to treat" basis. Scores are summarised as mean (SD), and comparisons made using 95\% confidence intervals (CIs) for difference in means. Binary data are presented as numbers, percentages, and relative risks (RRs), also with 95\% CIs. Statistical significance was tested using $t$ tests or $\chi^{2}$ tests, as appropriate. The Breslow-Day interaction test was used to examine whether the effect of a policy of ultrasound imaging on maternal anxiety was modified by whether or not the baby's hips were treated.

The second set of analyses presented here was explanatory, examining associations between psychosocial scores and early splinting, regardless of random allocation. For this analysis, we excluded at 8 weeks babies who started surgical treatment or had double nappies only in the first 8 weeks ( $\mathrm{n}$ $=16$ ), and at 1 year, we additionally excluded babies in whom abduction splinting or surgery had been initiated between 8 weeks and 1 year $(n=48)$. This allowed us to look at associations with early splinting per se excluding the possible effects of other or later treatments. These data were analysed using $t$ tests, with multiple regression to take account of potential confounding variables.

\section{RESULTS}

\section{Response rates}

Postal questionnaires were returned by $89 \%$ of mothers at 8 weeks and $79 \%$ at 1 year (fig 1 ). The responders for the psychosocial study were comparable to those in the trial as a whole.

\section{Intention to treat analysis}

The two randomised groups in this study were comparable in terms of important maternal and baby characteristics (table 2). Although at 8 weeks there were consistent trends towards less maternal stress in the ultrasound compared with the non-ultrasound group, none of these differences were significant for any of the psychosocial outcomes (table 3 ). The average scores for many of the outcomes were lower at 1 year than at 8 weeks, but did not differ by randomised group, and there were no suggestions of any consistent trends (table 4). There was no evidence that splint treatment of the babies modified the effect of the ultrasound policy on clinical levels of maternal anxiety (interaction $\chi^{2}=0.045$, $\mathrm{p}=0.848)$.

\section{Explanatory analysis}

Splinted and non-splinted groups were comparable in terms of social class, maternal age, marital status, birth weight, and gestational age. Splinting and maternal distress at 8 weeks were significantly associated (table 5). Mothers whose babies

Table 4 Psychosocial scores at 1 year by random allocation

\begin{tabular}{|c|c|c|c|c|c|c|c|c|c|}
\hline & \multicolumn{9}{|c|}{ Random allocation } \\
\hline & \multicolumn{3}{|c|}{ Ultrasound } & \multicolumn{3}{|c|}{ No ultrasound } & \multirow[b]{2}{*}{$\mathrm{p}$ Value } & \multirow[b]{2}{*}{ RR } & \multirow[b]{2}{*}{$95 \% \mathrm{Cl}$} \\
\hline & $\mathrm{N}$ & $\%$ & & $\mathrm{~N}$ & $\%$ & & & & \\
\hline \multirow[t]{2}{*}{ Anxiety in clinical range } & $54 / 234$ & 23 & & $62 / 243$ & 26 & & 0.53 & 0.90 & 0.66 to 1.24 \\
\hline & No & Mean & SD & No & Mean & SD & $\mathrm{p}$ Value & MD & $95 \% \mathrm{Cl}$ \\
\hline Anxiety scale (STAl) & 234 & 34.0 & 11.4 & 243 & 34.3 & 10.9 & 0.75 & -0.3 & -2.3 to 1.7 \\
\hline Depression (EPDS) & 238 & 7.0 & 5.1 & 243 & 6.8 & 4.7 & 0.79 & 0.1 & -0.8 to 1.0 \\
\hline Parenting stress total (PSI) & 211 & 66.4 & 12.8 & 219 & 66.1 & 13.2 & 0.85 & 0.2 & -2.2 to 2.7 \\
\hline PSI sense competence & 234 & 22.7 & 5.7 & 242 & 22.6 & 5.7 & 0.77 & 0.2 & -0.9 to 1.2 \\
\hline PSI attachment & 234 & 10.8 & 2.9 & 241 & 10.2 & 2.8 & 0.05 & 0.5 & 0.0 to 1.0 \\
\hline PSI child moody & 237 & 8.7 & 2.7 & 245 & 8.7 & 2.7 & 0.92 & 0.0 & -0.5 to 0.5 \\
\hline PSI child rewarding & 235 & 8.6 & 2.4 & 247 & 8.8 & 2.6 & 0.62 & -0.1 & -0.6 to 0.3 \\
\hline PSI spouse & 224 & 15.7 & 4.5 & 233 & 15.9 & 4.6 & 0.56 & -0.3 & -1.1 to 0.6 \\
\hline Hip worries inventory & 238 & 18.2 & 5.2 & 250 & 18.2 & 5.4 & 0.98 & 0.0 & -0.9 to 1.0 \\
\hline
\end{tabular}

MD, Mean difference; RR, relative rate; Cl, confidence interval; EPDS, Edinburgh postnatal depression scale; PSI, parenting stress index; STAI, Spielberger statetrait anxiety inventory. 
Table 5 Associations between splinting and psychosocial scores at 8 weeks

\begin{tabular}{|c|c|c|c|c|c|c|c|c|c|}
\hline & \multicolumn{3}{|c|}{ Splinted before 8 weeks } & \multicolumn{3}{|c|}{ Not splinted before 8 weeks } & \multirow[b]{2}{*}{ p Value } & \multirow[b]{2}{*}{ RR } & \multirow[b]{2}{*}{$95 \% \mathrm{Cl}$} \\
\hline & $\mathbf{N}$ & $\%$ & & $\mathbf{N}$ & $\%$ & & & & \\
\hline \multirow[t]{2}{*}{ Anxiety in clinical range } & $75 / 222$ & 34 & & $67 / 317$ & 21 & & 0.00 & 1.60 & 1.21 to 2.12 \\
\hline & No & Mean & SD & No & Mean & SD & p Value & MD & $95 \% \mathrm{Cl}$ \\
\hline Anxiety scale (STAI) & 222 & 37.3 & 13.2 & 317 & 33.5 & 10.9 & 0.00 & 3.8 & 1.7 to 5.9 \\
\hline Depression (EPDS) & 222 & 7.8 & 4.7 & 318 & 7.2 & 4.4 & 0.19 & 0.5 & -0.3 to 1.3 \\
\hline Parenting stress total (PSI) & 213 & 42.4 & 9.8 & 309 & 41.7 & 9.4 & 0.46 & 0.6 & -1.1 to 2.3 \\
\hline PSI sense competence & 220 & 22.7 & 6.4 & 316 & 22.7 & 6.0 & 0.87 & 0.1 & -1.0 to 1.1 \\
\hline PSI attachment & 220 & 9.5 & 2.6 & 316 & 9.7 & 2.6 & 0.48 & -0.2 & -0.6 to 0.3 \\
\hline PSI child moody & 218 & 9.9 & 3.2 & 315 & 9.5 & 3.2 & 0.08 & 0.5 & -0.1 to 1.0 \\
\hline Hip worries inventory & 222 & 30.6 & 7.2 & 319 & 23.8 & 5.9 & 0.00 & 6.8 & 5.6 to 7.9 \\
\hline
\end{tabular}

were splinted before 8 weeks were more likely to have anxiety scores in the clinical range than those whose babies were left untreated (RR 1.60; 95\% CI 1.21 to $2.12 ; \mathrm{p}<0.001$ ). On the hip worries inventory, mothers of splinted babies expressed significantly more worries about their baby at 8 weeks (MD 6.8; 95\% CI 5.6 to 7.9; $\mathrm{p}<0.001$ ). There were no significant associations between splint treatment and maternal depression or any aspects of parenting stress at 8 weeks. By 1 year, there were no longer any differences between mothers of splinted and untreated babies with respect to anxiety scores (table 6), although hip worries remained significantly higher in the splinted group at 1 year. Treatment with abduction splinting remained independently and significantly associated with hip worries score at 8 weeks and 1 year after adjustment for random allocation, gestational age, birth weight, parity, maternal age, marital status, and social class (data available but not shown).

\section{DISCUSSION}

These psychosocial findings complement the clinical results of this trial ${ }^{9}$ in showing that a policy of using ultrasound has no detectable adverse effects on the child's hip development, or on the mothers' distress or her perception of the emerging mother-child relationship.

Early splint treatment was associated with significantly higher levels of maternal anxiety at 8 weeks, as well as more hip worries both at 8 weeks and 1 year. Mothers of babies splinted in the early weeks of life continued to have higher levels of worries about hips at 1 year, despite the fact that, for all but a few babies, treatment had ended many months earlier.
As the ultrasound policy led to less splinting, it is somewhat surprising that there were no beneficial effects of imaging on maternal distress. This may reflect the fact that differences in splinting rates between the two trial arms, although significant, are not large enough to affect psychosocial scores by randomised group. Alternatively, psychosocial harms and benefits may both be present, but mediated through different mechanisms which, to some extent, balance each other out. Thus, although ultrasound may reduce distress for reasons already discussed, it may also increase distress because treatment decisions have to await the results of the ultrasound.

The associations found between maternal distress and splinting are important in confirming, in a large multicentre study, the concerns expressed informally by parents about splinting to clinicians and the parent support group, steps. ${ }^{18}$ It must be stressed that we cannot be sure that these are "effects" of splinting, as the design of this part of the study is non-randomised; however, other demographic and obstetric factors are unlikely to explain these associations. It appears that mothers worry, perhaps appropriately, about hip related issues in the splinted groups and have raised levels of anxiety. However, some of these anxieties remain several months after splint treatment has finished. It is encouraging, however, to note that this group of mothers as a whole, who have very young babies with a potentially disabling condition, do not appear to suffer other potentially serious effects such as raised scores on a depression screening instrument, compared with general population norms. This applies equally to mothers of splinted and non-splinted babies. On the other hand, about a quarter of mothers, $27 \%$ (150/555), were assessed as having clinically significant anxiety at

Table 6 Associations between splinting and psychosocial scores at 12 months

\begin{tabular}{|c|c|c|c|c|c|c|c|c|c|}
\hline & \multicolumn{3}{|c|}{ Splinted before 8 weeks } & \multicolumn{3}{|c|}{ Not splinted before 8 weeks } & \multirow[b]{2}{*}{$p$ Value } & \multirow[b]{2}{*}{ RR } & \multirow[b]{2}{*}{$95 \% \mathrm{Cl}$} \\
\hline & $\mathrm{N}$ & $\%$ & & $\mathrm{~N}$ & $\%$ & & & & \\
\hline \multirow[t]{2}{*}{ Anxiety in clinical range } & $35 / 161$ & 22 & & $59 / 252$ & 23 & & 0.69 & 0.93 & 0.64 to 1.34 \\
\hline & No & Mean & SD & No & Mean & SD & $\mathrm{p}$ Value & MD & $95 \% \mathrm{Cl}$ \\
\hline Anxiety scale (STAl) & 161 & 33.7 & 10.7 & 252 & 33.8 & 10.8 & 0.94 & -0.1 & -2.2 to 2.1 \\
\hline Depression (EPDS) & 162 & 6.8 & 4.2 & 254 & 6.9 & 5.1 & 0.80 & -0.1 & -1.1 to 0.8 \\
\hline Parenting stress total (PSI) & 149 & 66.3 & 13.2 & 224 & 66.2 & 13.1 & 0.96 & 0.1 & -2.7 to 2.8 \\
\hline PSI sense competence & 164 & 22.3 & 5.6 & 248 & 22.9 & 5.7 & 0.32 & -0.6 & -1.7 to 0.6 \\
\hline PSI attachment & 164 & 10.5 & 3.0 & 247 & 10.6 & 2.8 & 0.55 & -0.2 & -0.7 to 0.4 \\
\hline PSI child moody & 166 & 8.9 & 2.9 & 252 & 8.6 & 2.7 & 0.34 & 0.3 & -0.3 to 0.8 \\
\hline PSI child rewarding & 166 & 8.8 & 2.7 & 252 & 8.6 & 2.5 & 0.49 & 0.2 & -0.3 to 0.7 \\
\hline PSI spouse & 159 & 15.9 & 4.5 & 239 & 15.6 & 4.6 & 0.43 & 0.4 & -0.6 to 1.3 \\
\hline Hip worries inventory & 169 & 18.6 & 5.1 & 254 & 17.2 & 5.4 & 0.01 & 1.3 & 0.3 to 2.4 \\
\hline
\end{tabular}

MD, Mean difference; RR, relative rate; Cl, confidence interval; EPDS, Edinburgh postnatal depression scale; PSI, parenting stress index; STAI, Spielberger statetrait anxiety inventory. 
8 weeks. Little is known about whether postnatal anxiety has long term adverse effects, or whether this figure reflects the understandable and mostly short lived concerns of a group of mothers whose babies have a potentially serious condition. Although we could find no studies using this measure with a large comparable sample in the early months of life, our figures are comparable with studies of women undergoing antenatal screening. ${ }^{20} 231$

It is worth noting that scores on measures tapping aspects of the mother-baby relationship were not associated with splinting, as measured by the PSI. It appears that splinting may lead to worries about the baby's hips, but does not appear to be associated with a mother's wider distress about her relationship with the baby, including her enjoyment of the child, her sense of attachment or competence as a parent, or her negative feelings about the child. Other researchers have speculated on the links between neonatal ill health and the mother-child relationship, suggesting that a vulnerable infant may attract more attentive and positive parenting, and thus contribute to a stronger attachment relationship. It is possible that any such effects are complex and depend on other factors such as social context and support surrounding the family and the birth. Thus for some mothers, it may be that splinting leads to a closer relationship with the baby, whereas for others it may lead to feelings of rejection, or irritation at the circumstances of the problem. In a smaller study, it may have been possible to measure the mother-child relationship more directly through observation, and the limitations of questionnaire measures for this purpose are acknowledged.

Additional limitations of the study should be considered. The findings may underestimate maternal distress in the first month or so of life, as by 8 weeks, some babies had finished splint treatment. It is plausible that distress at 12 months may have depended to some extent on how reassuring or otherwise were the results of the $12-14$ month $x$ ray examination. In this pragmatic trial, it was not possible for us to control the timing of the clinical assessment. In many cases, however, the questionnaire assessment took place before the 12-14 month $x$ ray examination, making it unlikely to have a major impact on the findings. All data were gathered postally, as it was not possible in a large trial to visit each mother and baby. Although the EPDS was designed to be administered face to face, several substantial community studies have validated the postal use of EPDS. Moreover, response rates were very high, and we used standardised and well known questionnaires, apart from the infant hip worries inventory. This was designed specifically for this trial to reflect the concerns of mothers of babies with hip problems, after in depth pilot interviews and consultation with users' groups. Initial analysis of its psychometric properties suggests that these are comparable to those of well established instruments. An item in the 8 weeks scale about social support was omitted from the analyses because it showed low correlations with other items. Nevertheless, the findings (tables 3 and 5) are unaffected by the inclusion of this item (data not shown).

We believe that this is the first published study of the psychosocial effects on the family of having a baby with suspected NHI, and the first within the context of a large multicentre, randomised controlled trial. It provides important and novel information about maternal perceptions of and responses to ultrasound imaging and early treatment with abduction splinting over the first year of life. This is a pragmatic trial, encompassing the diversity of practice for managing babies with NHI seen in different hospital centres, managed by different specialists, and with varying policies. Thus the findings are likely to be generalisable beyond the context of this trial.
Summary of hip trial design and clinical results (published in full in Elbourne et $a^{9}{ }^{9}$ )

Study population: newborn infants found on routine newborn screening examination to have neonatal hip instability (NHI).

Eligibility: Age less than 43 days; $\mathrm{NHI}$ confirmed by a senior doctor; parental consent obtained.

Design: Randomised controlled trial using central telephone randomisation service.

Setting: United Kingdom and Ireland.

Assessment:

Ultrasound (US) group: assessment with ultrasound at or after 2 weeks of age before treatment decision made.

Non-US (NU) group: no assessment with ultrasound until after treatment decision made.

\section{Management:}

US group: immediate splinting if significant sonographic displacement or instability in one or both hips; monitoring with ultrasound and treatment at discretion of the responsible clinician if minor sonographic displacement or instability only. Hips to be splinted if persistence of abnormality beyond 8 weeks of age.

NU group: treatment decisions to be based on clinical examination. No ultrasound to be used to guide clinical management before treatment.

Hip radiograph at 12-14 months, and, for those with abnormalities, repeated at 2 years.

\section{Outcomes:}

Primary: abnormal hip radiographic appearances, operative treatment, abduction splinting, and walking by 2 years.

Secondary: resource use and costs, psychosocial consequences.

Analysis: Intention to treat.

Results: 629 babies (314 in US group; 315 in non-US group) recruited from 33 centres.

Clinical effects: Radiographic information available for $91 \%$ by $12-14$ months and $85 \%$ by 2 years. The groups were comparable at trial entry. 285 babies received hip treatment, including 248 splinted in the first 8 weeks of life. Fewer children in the US group had abduction splinting in the first 2 years (RR $0.78 ; 95 \% \mathrm{Cl} 0.65$ to $0.94 ; p=0.01$ ). Operative treatment was required by 21 US $(6.7 \%)$ and 25 $\mathrm{NU}(7.9 \%$ ) infants (RR $0.84 ; 95 \% \mathrm{Cl} 0.48$ to 1.47 ). By 2 years, abnormal hip radiographic appearances were identified on one or both hips of 21 US and 21 NU children (RR 1.00; $95 \% \mathrm{Cl} 0.56$ to 1.80). One US and four NU children were not walking by 2 years (RR 0.25 ; exact $95 \% \mathrm{Cl}$ 0.03 to $2.53 ; p=0.37$ ). US infants incurred significantly higher ultrasound costs over the first 2 years ( $£ 42 v £ 23$, mean difference $£ 19,95 \% \mathrm{Cl} £ 11$ to $£ 27$; total hospital costs were lower for US infants, but the difference was not significant.

Conclusions: The use of US imaging in infants with screen detected clinical hip instability allows abduction splinting rates to be reduced, and is not associated with an increase in abnormal hip development or higher rates of operative treatment by 2 years of age, or significantly higher costs.

Our findings suggest that maternal distress should be taken into account when considering the value of policies that extend the use of ultrasound imaging to all infants. These policies have been adopted in some countries and are likely to increase the numbers of infants offered early treatment with abduction splinting, ${ }^{32}{ }^{33}$ and therefore potentially increase distress. Furthermore, they suggest that, in screening and treatment trials for other chronic conditions, it 
may be helpful to take carer burden into account, in order fully to examine costs and benefits of different policies. This trial highlights the importance of extensive consultation with parents and their support groups in determining relevant outcomes for trials and in developing instruments for measuring the psychosocial burdens associated with ultrasound imaging and treatment, which complement the clinical and economic outcomes.

\section{ACKNOWLEDGEMENTS}

We thank the following: 629 children and their parents who took part in the trial; the parents who helped with piloting; the Department of Health/Medical Research Council for funding; Sue Banton and the parent support group, steps, $\mathrm{R}$ Collins and colleagues at the Clinical Trial Service Unit, Oxford for the randomisation service; the Data Monitoring Committee; G Bennett, A Grant, D Hall, E Hey, R MacFaul, and N Mays, and colleagues at the NPEU and elsewhere for their helpful advice and encouragement.

\section{CONTRIBUTORS}

$\mathrm{DE}, \mathrm{CD}, \mathrm{FG}, \mathrm{AG}$ designed the study. FG will act as guarantor. AQ collected and AK managed the data. FG, DE, CD, and AK carried out the analysis. All authors contributed to developing the protocol and writing.

\section{Authors' affiliations}

F Gardner, Department of Social Policy and Social Work, University of Oxford, Oxford, UK

C Dezateux, Centre for Paediatric Epidemiology and Biostatistics, Institute of Child Health, London, UK

D Elbourne, Medical Statistics Unit, London School of Hygiene and Tropical Medicine, London, UK

A Gray, Health Economics Research Centre, Department of Public Health, University of Oxford

A King, A Quinn, National Perinatal Epidemiology Unit, University of Oxford

Competing interests: none declared

Writing committee: C Dezateux, D Elbourne, F Gardner, A Gray, A King, A Quinn

Trial steering committee: R Arthur, S Bird, NMP Clarke, C Dezateux, D Elbourne, F Gardner, A Gray, A King, M Maclean (MRC), C Normand (chair), A Quinn, G Russell

Data monitoring committee: D Field, W Gillespie, I Leck, J Whitehead Imaging panel: R Arthur, J Fairhurst, D Pilling

Hip trial team Oxford: $\mathrm{H}$ Ashurst, S Ayers, C Bowen, L Brandon, J Fooks, A King, J MacLennan, L Morgan, M Marques, A Quinn, A Wrotchford Hip centres: Alder Hey and Liverpool Women's Hospitals, Liverpool (RWI Cooke, S Crawford, R Davis, R Massey, D Pilling, B Yoxhall, Dorgan, C Bruce); Altnagelvin Area Hospital, Londonderry (S Elliott, R Wray); Broomfield and St John's Hospitals, Chelmsford (AP Lipscomb, S Rao, J Tuite); East Glamorgan NHS Trust, Pontypridd (C Davies, J Moorcraft, J Murray); North Staffordshire Hospital, Stoke-on-Trent (DSK Brookfield, D Edwards, J Egginton, P Roberts, JSM Dwyer); Newcastle General Hospital, Freeman Hospital and Royal Victoria Infirmary, Newcastle (MP Ward Platt, AJ Chippindale, R Hornby, AP Kenna, AJ Grainger); North Tees General Hospital, Stockton-on-Tees (J Jani, W Thompson, CJ Tulloch, IG Verber); Royal Bournemouth Hospital, Bournemouth and Poole Hospital, Poole (V Arnett, J Brailsford, N J Fiddian, Z Parrott); Queen Elizabeth Hospital, Gateshead (J Hall, S Shanker, A Steele, M Higgs); Queen's Medical Centre, Nottingham (R Dove, J Hunter, P Twining); Royal Aberdeen Children's Hospital, Aberdeen (L Gomersall, J McLauchlan, JA Reid); Royal Belfast Hospital for Sick Children, Belfast (H Cowie, L Sweeney, T Taylor); Royal Devon and Exeter Hospital, Exeter (D Jameson Evans, J Harington, M Quinn); Royal Hospital for Sick Children, Glasgow (J Gray, E Loomes, DAK Parker, J Sherlock, A Hollman (deceased)); Royal Shrewsbury Hospital, Shrewsbury and The Robert Jones/Agnes Hunt Orthopaedic Hospital, Oswestry (J Morris, A Roberts, H Watson, RJ Welch); Southampton General Hospital, Southampton (NMP Clarke, J Fairhurst); Southmead Hospital, Bristol (T Chambers, E Loveday, M Simmonds, M Hubble); St Mary's/Queen Alexandra, Portsmouth (M Ashton, RH Richards); St Michael's Hospital, Bristol (D Grier, G Russell); Sunderland Royal Hospital, Sunderland (R Checketts, J Connor, M Otterburn, S Richmond); Taunton and Somerset Hospital, Taunton (D Challacombe, P Ewings, C Ogilvie); University Hospital of Wales, Cardiff and Llandough Hospital,
Penarth (M Abouharb, PHT Cartlidge, G Graham, K Lyons, G Pask, M Alfaham, L Ottery); The General Infirmary at Leeds (R Arthur, AB Gill, P Scott, JM Abberton); Whittington and The Royal Free Hospitals, London (D Eastwood, J Haddock, H Mackinnon, V Van Someren, A Washington); University College Hospital, Galway (B Curtin, B Loffus, C Nolan, D O'Keeffe); Wexham Park Hospital, Slough and Heatherwood Hospital, Ascot (C Luck, J Scrutton, R Jones, M Swan, Mr Unwin, B Wobi); Walsall Trust Hospital, Walsall (H Batra, D Drew, L Holland, R Hodgson); Wycombe General, High Wycombe (C Charlesworth, A Earley, KSH Wise)

\section{REFERENCES}

1 Standing Medical Advisory Committee. Screening for the detection of congenital dislocation of the hip in infants. London: Department of Health and Social Security, 1966.

2 Standing Medical Advisory Committee and the Standing Nursing and Midwifery Advisory Committee. Screening for the detection of congenital dislocation of the hip. London: Department of Health and Social Security, 1986.

3 Dezateux C, Godward S. Screening for congenital dislocation of the hip in the newborn and young infants. In: David TJ, eds. Recent advances in paediatrics. Edinburgh: Churchill-Livingstone, 1998:41-58.

4 Patel H. Preventive health care, 2001 update: screening and management of developmental dysplasia of the hip in newborns. Can Med Assoc $J$ 2001; 164:1669-77.

5 Dezateux C, Godward S. Evaluating the national screening programme for congenital dislocation of the hip. J Med Screen 1995;2:200-6.

6 Holen KJ, Tegnander A, Eik-Nes SH, et al. The use of ultrasound in determining the initiation of treatment in instability of the hip in neonates. $J$ Bone Joint Surg $[\mathrm{Br}]$ 1999:81:846-51.

7 Dezateux C, Godward S. A national survey of screening for congenital dislocation of the hip. Arch Dis Child 1996;74:445-8.

8 Gardiner HM, Dunn PM. Controlled trial of immediate splinting versus ultrasonographic surveillance in congenitally dislocatable hips. Lancet 1990;ii:1553-6.

9 Elbourne D, Dezateux C, Arthur R, on behalf of the UK Collaborative Hip Trial Group, et al. Ultrasonography in the diagnosis and management of developmental hip dysplasia (UK Hip Trial): clinical and economic results of a multicentre randomised controlled trial. Lancet 2002;360:2009-17.

10 Kumar R, Robson K. A prospective study of emotional disorder in childbearing women. Br J Psychiatry 1984; 144:35-47.

11 Eiser C. Psychological effects of chronic disease. J Child Psychol Psychiatry 1990;31:85-98.

12 Stein A, Cooper P, Campbell E, et al. Social adversity and perinatal complications: their relation to postnatal depression. BMJ 1989;298 1073-4

13 Warner R, Appleby L, Whitton A, et al. Demographic and obstetric risk factors for postnatal psychiatric morbidity. Br J Psychiatry 1996; 168:607-11.

14 Goldberg S, Simmons RJ. Chronic illness and early development. The parent's perspective. Pediatrician 1988;15:13-20.

15 Offord DR, Boyle MH, Fleming JE, et al. Summary of selected results from the Ontario Child Health Study. Can J Psychiatry 1989;34:483-91.

16 Rutter M, Tizard J, Whitmore K. Education, health and behaviour. London: Longman, 1970.

17 Standen PJ. The long-term psychological adjustment of children treated for congenital dislocation of the hip. Psychol Med 1983;13:847-54.

18 steps: The National Association for Children with Lower Limb Abnormalities. Secretary: Sue Banton, Lymm Court, 11 Eagle Brow, Lymm, Cheshire, WA13 OLP, UK. www.steps-charity.org.uk.

19 Abidin R. Manual for the Parenting Stress Index. Charlottesville, VA: Pediatric Psychology Press, 1986.

20 Hall S, Bobrow M, Marteau TM. Psychological consequences for parents of false negative results on prenatal screening for Down's syndrome: retrospective interview study. BMJ 2000;320:407-12.

21 Affleck G, Tennen H, Rowe J, et al. Mothers' remembrance of newborn intensive case: a predictive study. J Pediatr Psychol 1990;15:67-81.

22 Goldberg S, Morris P, Simmons RJ, et al. Chronic illness in infancy and parenting stress: a comparison of three groups of parents. J Pediatr Psychol 1990;15:347-58

23 Marteau TM, Bekker H. The development of a six-item short form of the Spielberger state-trait anxiety inventory (STAI). Br J Clin Psychol 1992;31:301-6.

24 Cox J, Holden R, Sagovsky R. Detection of postnatal depression: development of the 10-item Edinburgh Postnatal Depression Scale. Br J Psychiatry 1987; 150:728-86.

25 Appleby L, Gregoire A, Platz C, et al. Screening for high risk of postnatal depression. J Psychosom Res 1994;38:539-45.

26 Cooper PJ, Murray L, Hooper R, et al. The development and validation of a predictive index for postpartum depression. Psychol Med 1996;26:627-34

27 Thorpe K. A study of the Edinburgh Postnatal Depression Scale for use with parent groups outside the postpartum period. J Reprod Infant Psychol 1993;11:119-25.

28 Cox J. Origins and development of the 10-item Edinburgh Postnatal Depression Scale. In: Cox J, Holden J, eds. Perinatal psychiatry. London: Gaskell, 1994:115-24. 
29 Shakespeare J. Evaluation of screening for postnatal depression against the NSC handbook criteria. Prepared for a working party, June 2001. http:// www.nelh.nhs.uk/screening/adult_pps/postnatal_depression.html. Accessed 24 March, 2004.

30 Green JM, Murray D. The use of the Edinburgh Postnatal Depression Scale in research to explore the relationship between antenatal and postnatal dysphoria. In: Cox J, Holden J, eds. Perinatal psychiatry. London: Gaskell, 1994:180-98.
31 Miedzybrodzka ZH, Hall MH, Mollison J, et al. Antenatal screening for carriers of cystic fibrosis: randomised trial of stepwise vs couple screening. BMJ 1995;310:353-7.

32 Clegg J, Bache CE, Raut VV. Financial justification for routine ultrasound screening of the neonatal hip. J Bone Joint Surg [Br] 1999:81:852-7.

33 Altenhofen L, Allhoff PG, Niethard FU. Hip ultrasound screening within the scope of U3: initial experiences. Z Orthop Ihre Grenzgeb 1998;136:501-7.

\section{IMAGES IN NEONATAL MEDICINE}

\section{Getting knotted: umbilical knots in a monochorionic monoamniotic twin pregnancy}

$\mathrm{T}$

rue umbilical knots occur in about $1 \%$ of all pregnancies and are more common with long cords, grandmultiparity, male fetuses, polyhydramnios and monoamniotic twins. ${ }^{1}$ Figure 1 shows complex umbilical knotting in a monochorionic monoamniotic twin pregnancy. Delivery was by emergency section at 33 weeks gestation because of fetal distress. Apgar scores were 8 and 6 at one minute and 10 and 9 at five minutes and arterial blood cord $\mathrm{pH}$ values were 7.32 and 7.28 respectively.

The single cavity of the monoamniotic twin pregnancy allowed the separate cords to knot around each other. Fetal movements in utero or during the birth process may have increased tension in the knot compromising circulation resulting in fetal distress.

It is a major misconception that a knotted cord poses a major threat to the blood supply. Despite the compound appearance of the knots, both twins were born in good condition. Normal Apgar scores ${ }^{2}$ and cord $\mathrm{pH}$ values $^{3}$ are the usual outcome as reported in our case.

A A A Omari, D Cameron

Paediatric Department, Glan Clwyd Hospital, Sarn Lane, Clwyd LL18 5UJ; aika@omari1677.freeserve.co.uk

Competing interests: none declared

\section{REFERENCES}

1 Airas U, Heinonen S. Clinical significance of true umbilical knots: a population-based analysis. Am J Perinatol 2002; 19:127-32.

2 Sornes T. Umbilical cord knots. Acta Obstet Gynecol Scand 2000;79:157-9.

3 Maher TJ, Conti JA. A comparison of umbilical cord blood gas values between newborns with and without true knots. Obstet Gynecol $1996: 88: 863-6$

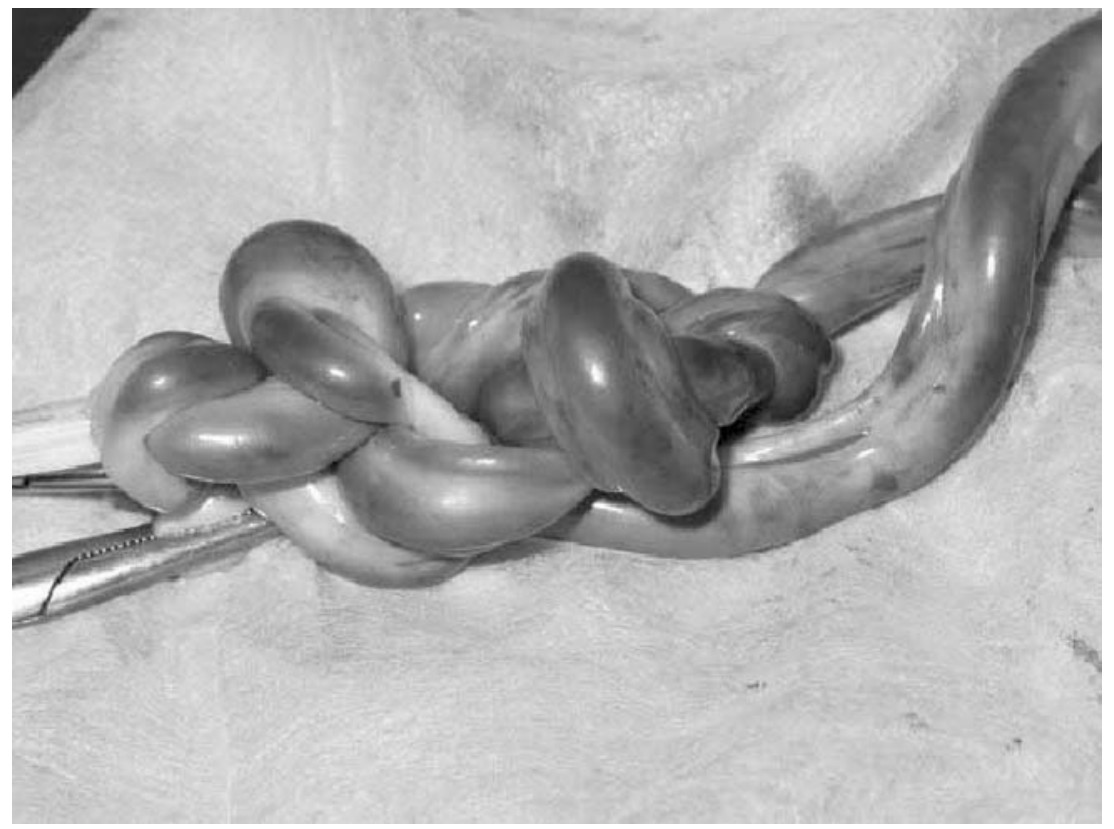

Figure 1 Complex umbilical knotting in a monochorionic monoamniotic twin pregnancy. 